\title{
Cleidocranial Dysplasia: A New Mutation
}

\author{
(D) Nimet Pınar Yılmazbaş ${ }^{1}$, (D) Diğdem Bezen ${ }^{1}$, (D) Biray Ertürk² \\ 1 istanbul Okmeydanı Training and Research Hospital, Clinic of Pediatrics, Istanbul, Turkey \\ 2istanbul Okmeydanı Training and Research Hospital, Clinic of Medical Genetics, İstanbul, Turkey
}

\section{Abstract}

Cleidocranial dysplasia is a rare disease with mostly autosomal dominant inheritance. De novo mutations are rare and the disease is characterized by generalized dysplasia of bone tissue. Delay in closure of cranial sutures and fontanels, short stature, dental anomalies, hypoplasic or aplasic clavicles and some other bone anomalies are seen clinically. A 9.5 month old infant who presented with anterior and posterior fontanelle enlargement and separated sagittal suture is presented in this paper.

Keywords: Cleidocranial dysplasia, enlarged fontanels, relative macrocephaly

\section{INTRODUCTION}

Cleidocranial dysplasia (CCD) is an autosomal dominant disorder with rare de novo mutations and with an incidence of $1 / 1000000$. It is generally seen as a result of mutations in the RUNX2 gene in chromosome $6 \mathrm{p} 21$ that regulates normal osteoblastic differentiation and appropriate bone formation (1,2). In such bone dysplasia, flat bones such as head bones, clavicle, and teeth are affected. Short stature, frontal and parietal bossing, seperated cranial sutures, late closure of fontanels, hypoplasia or aplasia of clavicles, maxilla hypoplasia, hypoplasia of iliac wings and brachydactyly can be seen. Although the eruption time of primary teeth is normal, early tooth loss may accompany in adulthood (1,3). In affected cases, the clavicles may not be present partially or completely. Therefore, increased opposition at the shoulders is a specific finding for this disease (4). The diagnosis is confirmed by clinical findings, radiological examinations and gene sequence analysis. Cases should be followed for orthopedic complications, dental anomalies, upper respiratory tract obstruction, sinus and ear infections, hearing loss, osteoporosis and osteopenia. There is no specific treatment for CCD. Bone deformities can be operated after 5 years of age and orthodontic intervention may be required due to tooth loss (5).

\section{CASE REPORT}

Written consent was obtained from the mother of the patient to present the case.

A 9.5 month old girl was admitted to the outpatient clinic with enlarged anterior and posterior fontanels and separated sagittal suture. The patient was the first child of a 24 year old mother and a 36 year old father from a non-consanguineous marriage. Birth weight was $3150 \mathrm{~g}$ [25-50\% percentile, standard deviation score (SDS): -0.51], birth height was $49 \mathrm{~cm}$ (25-50\% percentile, SDS: $-0.12 \%)$ and birth head circumference was $35 \mathrm{~cm}\left(50^{\text {th }}\right.$ percentile, SDS: 0.18). Her family history revealed short stature, early tooth loss, and similar facial dimorphism in her mother, uncle, two male cousins and her grandmother, but no cases were diagnosed. On physical examination, body weight was 8000 g (25-50\% p, SDS: -0.74), height was 69 cm (10-25\% p, SDS: -0.55), head circumference was $45.5 \mathrm{~cm}$ (50-75\% p, SDS: 1.05), weight by height was 99\% (SDS: -0.07 ), anterior fontanel was $4 \times 5$ $\mathrm{cm}$ and posterior fontanel was $2 \times 2 \mathrm{~cm}$, metopic-coronal and sagittal sutures were separated, and there were flattened nose and frontal bossing. The patient had two primary teeth and the other system examinations were normal (Figure 1). In terms of neuromotor development, the patient achieved head control at 3 months, supported sitting at 5 months and unsupported

Address for Correspondence: Nimet Pınar Yılmazbaş, İstanbul Okmeydanı Training and Research Hospital, Clinic of Pediatrics, İstanbul, Turkey

Phone: +90 5353217433 E-mail: drpinary@yahoo.com ORCID ID: orcid.org/0000-0002-1283-1712

Received: 11.06 .2018

Accepted: 05.10 .2018

Cite this article as: Yılmazbaș NP, Bezen D, Ertürk B. Cleidocranial Dysplasia: A New Mutation. Eur Arch Med Res 2019; 35 (4): 253-6

๑Copyright 2019 by the Health Sciences University, Okmeydanı Training and Research Hospital

European Archives of Medical Research published by Galenos Publishing House. 
sitting at 8 months. Our case erupted her first primary tooth at the age of 6 months and started to spell at 8 months. Laboratory tests were within normal limits as follows: thyroid stimulating hormone (TSH): 2.75 microlU/mL (0.73-8.35 microlU $/ \mathrm{mL})$, free T4: $1.26 \mathrm{ng} / \mathrm{dL}$ (0.92-1.99), calcium (Ca): $10.64 \mathrm{mg} / \mathrm{dL}$ (9-11 mg/ $\mathrm{dL}$ ), phosphorus $(\mathrm{P}): 6.2 \mathrm{mg} / \mathrm{dL}(4.5-6.7 \mathrm{mg} / \mathrm{dL})$, parathyroid hormone (PTH): $21.52 \mathrm{pg} / \mathrm{mL}(3.6-32 \mathrm{pg} / \mathrm{mL})$, and $25(\mathrm{OH})$ vitamin D: $32.9 / \mathrm{g} / \mathrm{L}(20-50 / \mathrm{g} / \mathrm{L})$. The alkaline phosphatase level of our case was $97 \mathrm{U} / \mathrm{L}$ and this value was close to the lower limit according to age (n: 70-1107 U/L). On the direct X-ray, sagittal suture and posterior fontanel were open, anterior fontanel was

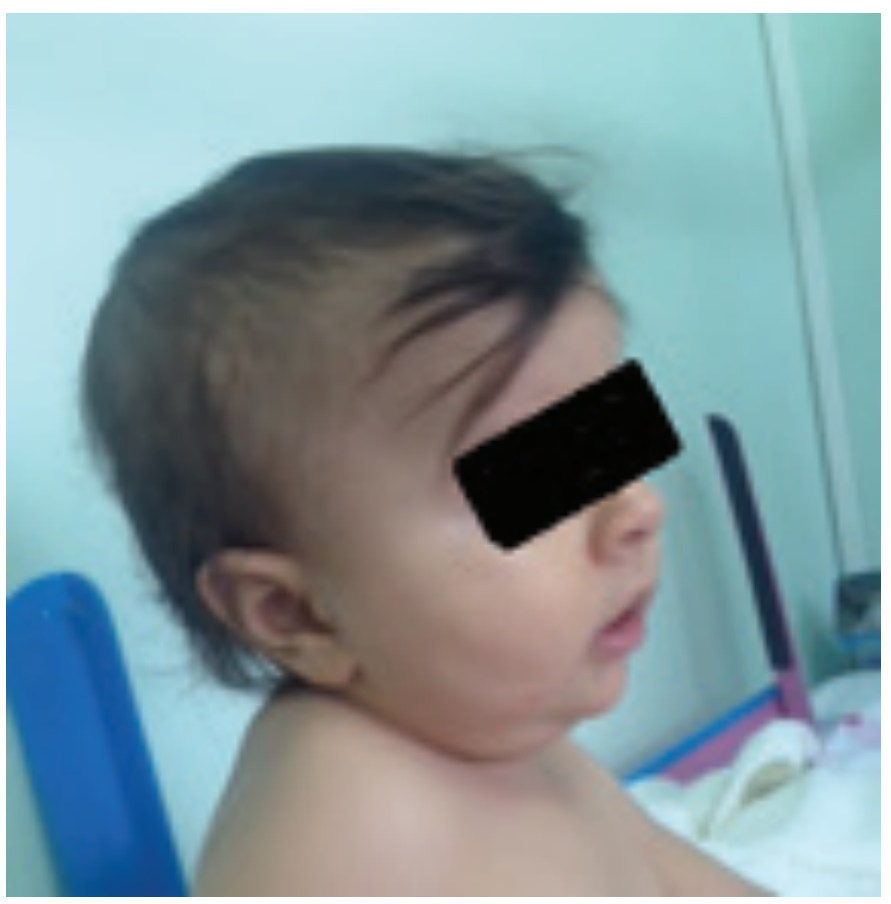

Figure 1. Side view of brachiocephalic head of case

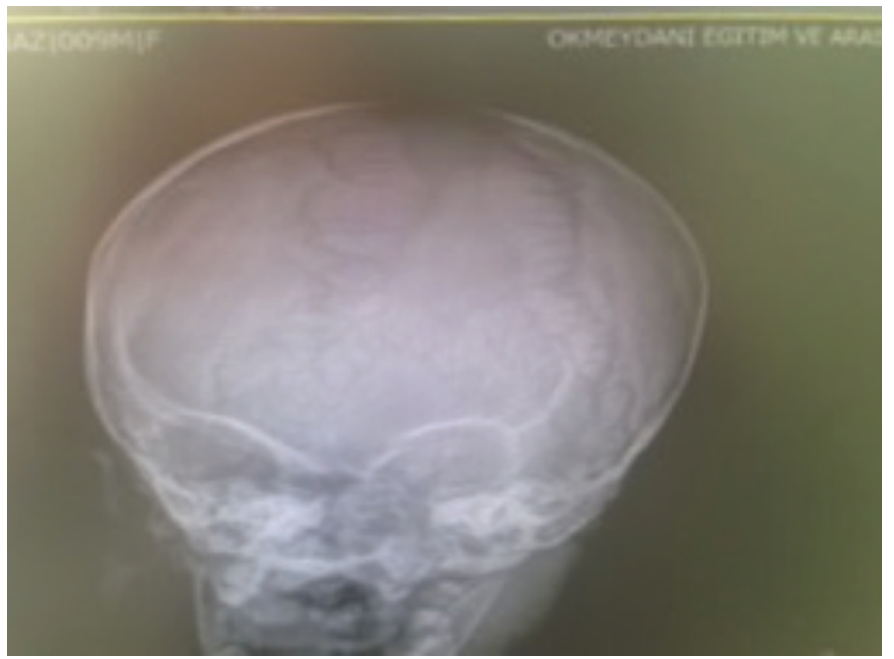

Figure 2. View of enlarged fontanels and sutures on anteroposterior posterior radiograph of the case large for age, clavicle development was normal and bone age was consistent with 6 months (Figure 2). On cranial ultrasound examination, the ventricular horn index was within normal limits, lateral ventricular contours were smooth, the $3^{\text {rd }}$ and $4^{\text {th }}$ ventricles were normal in size, localization and configuration, and cerebral-cerebellar hemispheres, basal ganglia, intra- and periventricular sites were in normal sonographic appearance. On physical examination of the mother of our case, height was $148 \mathrm{~cm}$, weight was 64 kilogram, and head circumference was 61 $\mathrm{cm}$. She had frontal bossing with $0.5 \mathrm{~cm}$ open anterior fontanelle and accompanying unilateral hip dysplasia. The mother had increased opposition of shoulders and was able to connect both shoulders to the midline. Based on these findings, a diagnosis of bone dysplasia was considered in the mother. Cranial ultrasonography was reported to be normal when we looked at the causes of large fontanelle, and no lesion causing intracranial pressure increase was detected and this diagnosis was ruled out. Ca, P, PTH and $25(\mathrm{OH})$ vitamin D levels were normal, so we ruled out the diagnosis of rickets. In our case, normal TSH and free T4 levels allowed us to rule out hypothyroidism that may cause large fontanelle. Hypophosphatasia, a rare hereditary disease associated with bone and dental mineral deficiency accompanied by low or normal autosomal recessive alkaline phosphatase, normal or high serum calcium and phosphate levels, is a disease that causes neuromotor growth retardation in the early period, and the neuromotor development of our case was normal according to the month and the tone was normal, so we ruled out this diagnosis $(6,7)$.

The present findings and family history of our case were suggestive of bone dysplasias. The increased opposition of shoulders in mother was specific for the diagnosis of CCD and RUNX2 gene mutation was sent from case and mother for definitive diagnosis. As a result of the sequence analysis, heterozygous c.1281delC (p.Gly428Alafs*56) mutation was detected in exon 8 in our case and mother, which was not previously defined. After the genetic diagnosis was confirmed, our case was consulted and followed-up with orthopedics and neurosurgery clinics. In addition, genetic counseling was provided to all affected cases in the family and thus orthodontic and orthopedic problems were intervened.

\section{DISCUSSION}

CCD is a genetic disease that occurs as a result of a mutation in the RUNX2 gene, which is involved in osteoblastic differentiation and function, with an incidence of 1/1000000. Flat bone anomalies such as head bones and clavicle, and tooth 
anomalies are present in each case. Short stature, frontal and parietal bossing, open cranial sutures, late closure of fontanels, hypoplasia or aplasia of clavicles, maxilla hypoplasia, hypoplasia of iliac wings, brachydactyly and early dental loss are the accompanying clinical conditions. Our case was admitted to our hospital because of an enlarged anterior and posterior fontanelle and he was admitted to another tertiary training and research center before his admission to our hospital; however, he could not be diagnosed as his laboratory findings and neuromotor development were normal. Hypothyroidism and rickets can cause enlarged fontanels in an infant of this age, but normal biochemical tests ruled out these diagnoses. In our case with normal cranial ultrasonography findings, diseases that could cause increased intracranial pressure were also ruled out. The serum alkaline phosphatase level of our case was at the lower limit and suggested the diagnosis of hypophosphatasia. While infantile hypophosphatasia is a disease with fontanel patency, bone mineralization disorder and low alkaline phosphatase in early infancy, it also causes neuromotor developmental retardation in the early period; however, normal neuromotor development, lack of hypotonicity and alkaline phosphatase level being not as low as in hypophosphatasia ruled out the diagnosis in our case. The presence of similar cases in the family of our case indicated a genetic disease. The presence of unilateral developmental dysplasia of the hip, open anterior fontanelle, increased opposition of the shoulders and accompanying tooth loss in the mother made us think of the diagnosis of CCD. Diagnosis was confirmed by gene analysis and a new mutation was detected. Since the majority of craniofacial anomalies are prominent in adolescence in this disease, the number of cases diagnosed during infancy is low (8-10). The mean age at diagnosis was reported to be 18.3 years in the study by Golan et al. (11) including 24 CCD cases. Our case is an early-diagnosed case and early diagnosis is important for endocrinological, orthopedic and orthodontic follow-ups and early interventions when necessary. In previous series, shortness of clavicle and increased opposition in CCD were reported to accompany $88 \%$ of cases (11). In the mother of our case, there was increased opposition in shoulder movements, but the clavicle size was normal on the bone radiographs of our case and there was no increased opposition movement. As indicated in previous publications, this shows us that $C C D$ can cause different clinical presentations among the same family members (12).

When the causes of fontanel patency are listed, bone dysplasia is a rare disease and diagnosis is therefore delayed. However, simple laboratory tests and radiological examinations can easily exclude other possible diagnoses. If the findings of other members of the family are carefully recorded, bone dysplasia should be considered and the diagnosis should be easier. With this case, we wanted to draw attention to the early findings of CCD and to emphasize the importance of early diagnosis.

Many patients are examined in healthy pediatric outpatient clinics due to the relative macrocephaly and enlarged fontanelle. Bone dysplasias should be considered when evaluating these patients, but these cases are not always diagnosed because they are rare. In this case report, we aimed to raise awareness of the rarely seen CCD and to emphasize the importance of early diagnosis.

\section{Ethics}

Informed Consent: Was taken.

Peer-review: Externally peer-reviewed.

\section{Authorship Contributions}

Surgical and Medical Practices: N.P.Y., Concept: N.P.Y., Design: D.B.,Data Collection or Processing: B.E., Analysis or Interpretation: D.B., N.P.Y., Literature Search: B.E., Writing: P.Y.

Conflict of Interest: No conflict of interest was declared by the authors.

Financial Disclosure: The authors declared that this study received no financial support.

\section{REFERENCES}

1. Mundlos S. Cleidocranial dysplasia: clinical and molecular genetics. J Med Genet 1999:36:177-82.

2. Ott CE, Leschik G, Trotier F, Brueton L, Brunner HG, Brussel W, et al. Deletions of the RUNX2 gene are present in about $10 \%$ of individuals with cleidocranial dysplasia. Hum Mutat 2010;31:E1587-E93.

3. Turek's Orthopaedics: Principles And Their Application. Lippincott Williams and Wilkins 2005.pp.251-2.

4. John J. Paul and Juhl's essentials of radiologic imaging, 7th ed. LippincottRaven 1998.

5. Pediatric Orthopedics in Practice. Springer 2007.p.478.

6. Soto E, Richani K, Gonçalves LF, Devers P, Espinoza J, Lee W, et al. Threedimensional ultrasound in the prenatal diagnosis of cleiodocranial dysplasiz associated with B-cell immundeficiency. Ultrasound Obstet Gynecol 2006;27:574-9.

7. Sağlam H, Erdöl Ș. Hipofosfatazya. Turkiye Klinikleri J Med Genet-Special Topics 2016;1:87-92.

8. Suba Z, Balaton G, Gyulai-Gaal S, Balaton P, Barabas J, Tarjan I. Cleidocranis dysplasia: diagnostic criteria and combined treatment. J Craniofac Surg 2005;16:11226.

9. Ringe KI, Schirg E, Galanski M. Cleidocranial dysplazia (CCD) causing respiratory distress syndrome in a newborn infant. A case report. J Radiol Case Rep 2010;4:9-12. 
10. Stewart PA, Wallerstein R, Moran E, Lee MJ. Early prenatal ultrasound diagnosis of cleidocranial dysplasia. Ultrasound Obstet Gynecol 2000;15:154-6.

11. Golan I, Baumert U, Hrala BP, Schaumburger J, Wiech O, Grifka J, et al.
Symptoms and signs in cleidocranial dysplasia (CCD) Z Orthop Ihre Grenzgeb 2003;141:336-40.

12. Cavalli P, Santorelli FM, Bontardelli M, Tessa A, Bosi A, Poggiani C. Prenatal exclusion of cleidocranial dysplasia Prenat Diagn 2003;23:945-6. 